\title{
Economia do Insumo-Produto: uma análise de impacto dos investimentos anunciados para o Espírito Santo entre 2011- 2016
}

\author{
Celso Bissoli Sessa \\ Marlon Porfírio Casotto²
}

\begin{abstract}
Resumo:
O objetivo é mensurar os impactos econômicos dos investimentos anunciados para o Espírito Santo entre 2011 e 2016 com base na MIP. Será apresentado um panorama da economia capixaba para contextualizar o cenário no qual ocorrerão os investimentos, bem como exposto o modelo de insumo-produto. Poderá verificar-se que caso todos os investimentos aconteçam, o impacto na economia capixaba será significativo, com setores apresentando crescimento pouco provável baseado na sua importância para o estado. Existem indícios de que os investimentos estejam superestimados em virtude do volume divulgado e da incerteza da efetividade da realização em sua integralidade no prazo de cinco anos.
\end{abstract}

Palavras-chave: Economia Capixaba, Matriz de Insumo-Produto, Impacto Econômico.

Input-output economics: an impact analysis of the investments announced for Espírito Santo for 2011-2016

\begin{abstract}
:
The objective is to measure the economic impact of investments announced for Espírito Santo in 2011-2016 from the MIP. An overview of the state economy to contextualize the scenario in which investments will occur and will be exposed to the input-output model will be presented. It can be seen that if all investments occur, the impact on the state economy will be significant, with sectors presenting unlikely growth based on its importance to the state. There is evidence that investments are overestimated because of the reported volume and the uncertainty of the effectiveness of achievement in their entirety within five years.
\end{abstract}

Keywords: Capixaba Economics, Matrix Input-Output, Economic Impact.

Classificação JEL: C67, D57, R15.

1 Professor do Departamento de Economia da Universidade Federal do Espírito Santo (UFES). E-mail: celso.bissoli@gmail.com

2 Bacharel em Ciências Econômicas pela Universidade Federal do Espírito Santo. E-mail: marlonmandino@yahoo.com.br 


\section{Introdução}

O investimento agregado em uma economia constitui um dos elementos mais importantes, devido à duplicidade de seu caráter: ao mesmo tempo em que o investimento é um dos principais componentes de curto prazo da demanda, essa variável também é considerada fundamental no crescimento de longo prazo de uma localidade (MAGALHÃES e TOSCANO, 2010). Nos últimos anos, a economia do Espírito Santo vem se destacando no cenário nacional por apresentar um crescimento acima da média nacional, baseado principalmente nas commodities (minério de ferro, aço, celulose, e, mais recentemente, petróleo e gás). Parte do crescente desenvolvimento econômico do estado é fruto dos desdobramentos dos investimentos nos Grandes Projetos (no período 1975-1990) e, mais recentemente, do desenvolvimento da indústria de petróleo e gás atrelado aos resultados do comércio internacional.

Segundo dados do Instituto Jones dos Santos Neves (2012), entre 2011 e 2016, a economia capixaba deve receber investimentos superiores a $\mathrm{R} \$ 100$ bilhões, o maior volume já identificado para o estado, distribuídos entre 1.373 projetos com valor médio de R $\$ 73,3$ milhões. Em termos agregados, o setor de energia é o que deve receber o maior volume de recursos $(40,3 \%)$, seguido do setor de indústria $(32,5 \%)$ e de comércio, e de serviço e lazer $(7,3 \%)$. No que diz respeito à distribuição regional dos investimentos, a região litoral sul e a região metropolitana receberão $45,5 \%$ e $25,2 \%$ dos investimentos, respectivamente.

Os investimentos previstos para o estado estão concentrados nos setores produtores de commodities de exportação, corroborando a hipótese de tendência ao aprofundamento do atual perfil da economia capixaba. Assim, em virtude do desempenho recente da economia do Espírito Santo e tendo em vista o grande volume de recursos que o estado pode vir a receber nos próximos anos, o objetivo é mensurar os impactos econômicos que serão gerados.

A mensuração do impacto econômico que os investimentos anunciados para o Espírito Santo, entre 2011 e 2016, trarão para a economia capixaba será feita com base na Matriz de Insumo-Produto e nos dados da pesquisa "Investimentos Anunciados para o Espírito Santo 2011-2016”, realizada pelo Instituo Jones dos Santos Neves (IJSN).

A principal contribuição deste trabalho reside na identificação das distribuições, intensidades e transmissões dos efeitos projetados no sistema produtivo da economia capixaba, especialmente considerando a geração de informações para as estratégias dos formuladores de política no estado. Caso todos os investimentos aconteçam, o impacto na economia capixaba será significativo, com setores apresentando crescimento pouco provável baseado na sua importância para o estado, havendo indícios de que os investimentos estejam superestimados em virtude do volume divulgado e da incerteza da efetividade da realização em sua integralidade no prazo de cinco anos. 
Para melhor entendimento, o artigo será dividido em três seções, além desta introdução e das considerações finais. $\mathrm{Na}$ seção 2, será apresentada uma breve discussão sobre desenvolvimento regional e um panorama da economia capixaba nas últimas décadas com a finalidade de apresentar o cenário no qual os investimentos já citados vão ocorrer. $\mathrm{Na}$ seção 3, será apresentado o modelo de insumo-produto, que servirá de base metodológica deste artigo para o estudo de impacto econômico. E, finalmente, a seção 4 será composta pelo estudo de impacto econômico realizado por meio da Matriz de Insumo-Produto do Espírito Santo. Essa seção conterá, ainda, uma breve descrição dos resultados obtidos, seguido pela última seção: as considerações finais.

\section{Desenvolvimento regional e caracterização econômica do Espírito Santo}

O debate sobre desenvolvimento regional enfatizou que o processo de crescimento econômico acontece de forma desigual entre as regiões. Nas palavras de Perroux (1955, p. 146), "o crescimento não aparece por toda a parte; manifesta-se em pólos de crescimento, com intensidades variáveis, expande-se por diversos canais e tem efeitos terminais variáveis no conjunto da economia". Na mesma direção, Myrdal (1957) argumentou, baseado no princípio da causalidade cumulativa, que as regiões tenderiam a seguir caminhos diferentes ao longo do tempo, pois os investimentos com maiores retornos concentrar-se-iam em algumas regiões e, em razão de crescentes economias internas e externas, esse processo tornar-se-ia cumulativo, embora houvesse efeitos de espraiamento (DINIZ, 2001). A concentração tenderia a ser permanente, pois os efeitos propulsores (ou de espraiamento) não seriam capazes de reverter esse processo, a não ser em algumas poucas regiões (WILTGEN, 1991). Hirschman (1958) também constatou que as regiões mais desenvolvidas atraíam mais investimentos em relação às regiões mais atrasadas, reforçando a desigualdade entre elas, mas também reconhecia a existência de alguns efeitos positivos sobre as regiões atrasadas (DINIZ, 2011).

Esses princípios do desenvolvimento desigual ajudam na compreensão da realidade regional do Espírito Santo, um estado marcado historicamente por diferenças econômicas em seu espaço geográfico. A caracterização dos três ciclos de desenvolvimento econômico ${ }^{3}$ pelos quais o estado passou ilustra o cenário econômico no qual acontecerão os investimentos anunciados entre 2011 e 2016, especialmente em relação ao $3^{\circ}$ ciclo, que ainda está em curso.

Até 1950, a economia capixaba foi caracterizada como agroexportadora baseada na cultura do café, produzido, em sua maior parte, em pequenas propriedades

3 A denominação ciclo de desen-volvimento possui aqui a conotação de períodos de desenvolvimento socioeconômico caracterizados por poucas atividades econômicas. 
e com mão-de-obra de predominância familiar. $\mathrm{O} 1^{\circ}$ ciclo de desenvolvimento do estado foi marcado justamente por essa característica, o que representa, de certa forma, um prolongamento da economia cafeeira que predominou no Brasil até o processo de industrialização capitaneado por São Paulo inicialmente e, mais tarde, estendido a outros estados do país (CAÇADOR, 2008).

Entre as décadas de 1850 e 1950, o Espírito Santo completou o processo de ocupação do interior do seu território, bem como passou a desenvolver suas cidades. O café ocupou o papel principal nesse período e foi o fator dominante na formação da economia regional do estado. Entretanto, a forma de produção adotada no Espírito Santo, baseada na pequena propriedade familiar e em sistemas de parceria, funcionou como ponto limitador de um processo mais robusto de desenvolvimento econômico e diversificação nas atividades produtivas (ROCHA, 1998).

Durante o $1^{\circ}$ ciclo, a economia cafeeira predominou como aspecto mais relevante na economia capixaba, proporcionando a ocupação do interior do estado devido às suas características de produção. Basicamente, até o fim da década de 1950, o café era a principal atividade da maior parte dos estabelecimentos rurais, além de gerar um terço da renda no estado e responder por mais de $40 \%$ da receita tributária. (MORANDI et al., 2012). Até a década de 1960, a população capixaba era de 1,4 milhões de habitantes, sendo que $71,55 \%$ dessa população viviam na zona rural em função da atividade cafeeira.

Esse cenário só teve um ponto de ruptura estrutural a partir da década de 1950, com a crise de superprodução e de preços do café que atingiu a cafeicultura nacional. Graças a uma política de erradicação dos cafezais implantada pelo governo federal pelo Grupo Executivo de Racionalização da Cafeicultura (Gerca), o Espírito Santo foi beneficiado com recursos financeiros que permitiram investimentos em infraestrutura para criar condições favoráveis ao processo de industrialização. Outro resultado da política de erradicação dos cafezais foi a grave crise social que teve como resultado um intenso processo de êxodo rural aliado a altas taxas de desemprego, afetando em torno de 240 mil pessoas (ROCHA e MORANDI, 1991).

A partir da década de 1960, o Espírito Santo passou por profundas alterações em sua estrutura produtiva. Ao longo de apenas 40 anos, sua economia de base preponderantemente agrícola e dependente da cultura do café passou a ter um perfil fortemente industrial, com setores de serviço e comércio, principalmente aqueles ligados ao comércio exterior, bastante desenvolvidos (MORANDI et al., 2012).

$\mathrm{O} 2^{\circ}$ ciclo de desenvolvimento pelo qual a economia capixaba passou pode ser divido em dois períodos devido às características do processo de industrialização e aos fatores envolvidos. A primeira fase compreende o período de 1960 a 1975 , caracterizada pela expansão dinâmica da economia local capitaneada pelo capital local e pautada no crescimento de pequenas e médias empresas, principalmente dos setores tradicionais (produtos alimentares, madeira, têxtil e minerais não metálicos) e de metalurgia. Assim, de acordo com Rocha e Morandi (1991), a indústria de transformação apresentou um desempenho no período de 1959 a 1975 bem supe- 
rior ao da década de 50, com taxa de crescimento anual acima de $15 \%$ e expansão em todos os gêneros, apesar de não se verificar diferenciação expressiva na sua estrutura industrial.

A primeira fase do $2^{\circ}$ ciclo de desenvolvimento foi marcada notadamente pelo crescimento pautado no capital local apoiado em financiamentos e incentivos fiscais proporcionados pelos governos federal e estadual. A partir da segunda metade da década de 1970, o Espírito Santo já apresentava infraestrutura portuária, de transportes e de abastecimento energético que possibilitaram a atração de novos investimentos, agora com um novo perfil e uma dinâmica completamente distintas da anterior (ROCHA e MORANDI, 1991). A primeira fase do ciclo pode ser entendida como um processo de transformações profundas, mas também que criou bases para a atração dos Grandes Projetos ${ }^{4}$.

O período entre 1975 e 1990 compreende a $2^{\text {a }}$ fase do segundo ciclo de desenvolvimento, que apresentou características como a ampla diversificação econômica, com o surgimento e desenvolvimento de setores não tradicionais (metalurgia, mecânica, química e material de transporte), bem como a presença marcante do grande capital, em sua maior parte de grupos nacionais e estrangeiros. Vale ressaltar que esse processo não eliminou a participação do capital local (ROCHA e MORANDI, 1991). Dessa forma, a economia capixaba passou a integrar a dinâmica da economia brasileira com um caráter complementar, principalmente no setor industrial, tornando-se um novo espaço de reprodução do "grande capital" (ROCHA e MORANDI, 1991).

Os Grandes Projetos (Aracruz Celulose, atualmente Fibria; Companhia Siderúrgica de Tubarão (CST), atualmente Arcellor Mittal Tubarão; e Samarco) que se instalaram no Espírito Santo, resultados do II Plano Nacional de Desenvolvimento (II PND), beneficiaram-se da conjuntura do mercado internacional e da estagnação da economia brasileira na década 1980.

Para Mota (2002), a crise da década de 1980 permitiu que o padrão de expansão industrial brasileiro baseado no mercado interno fosse rompido, criando possibilidades para o crescimento pontual de setores exportadores, principalmente nos setores de papel e celulose, metalurgia, produtos agroindustriais, química e indústria extrativa. Isso esboçou o perfil regional da economia brasileira na década de 1990, com regiões ligadas mais fortemente ao mercado externo.

Em síntese, o $2^{\circ}$ ciclo de desenvolvimento caracterizou-se por profundas mudanças, tanto na estrutura econômica do Espírito Santo quanto em termos sociais, uma vez que em 1960 a população urbana representava $28,45 \%$ da população total e em 1990 esse número já era de 78\%. Nessas três décadas, nota-se uma ruptura da economia baseada predominantemente na cafeicultura, passando para uma estrutura com perfil industrial-urbano e de serviços (ROCHA, 1998). Observa-se tam-

4 O termo Grandes Projetos refere-se aos investimentos realizados em plantas industriais produtoras de commodities no estado entre meados de 1970 e início de 1980. 
bém que grande parte da população urbana instalou-se na Região Metropolitana da Grande Vitória e que a economia capixaba passou por um fortalecimento na lógica de desenvolvimento regional com a ampliação e diversificação da base produtiva, com o PIB crescendo à taxas anuais superiores às da economia brasileira (MORANDI et al., 2012).

$\mathrm{Na}$ década de 1990, o Brasil passou por um intenso processo de mudanças político-institucionais e econômicas: ruptura do Modelo de Substituição de Importações (MSI); eleições diretas para presidente, o que não acontecia desde 1960; privatizações; Consenso de Washington e Plano Brady; abertura comercial e financeira; e estabilização da economia a partir de 1994 com a implantação do Plano Real. Para Castro (2005), entre 1990 e 1994, o Brasil passou por uma mudança em seu "modelo" de crescimento. Após dez anos sem investimentos e em luta (sem sucesso) contra a inflação, o processo de crescimento baseado no MSI chegou ao limite. A década de 90 foi marcada pelo início do processo de privatização e pela abertura econômica. Em meio a todo esse cenário, verificou-se que o crescimento da economia capixaba $(3,9 \%)$ se manteve superior à média nacional $(2,4 \%)$, conforme Tabela 1. Os Grandes Projetos industriais continuaram a influenciar de forma crucial e decisiva a dinâmica da economia estadual. Os fatores mais relevantes que promoveram o desempenho econômico capixaba nesse período foram: o crescimento das importações estaduais por meio das companhias importadoras (tradings), beneficiadas pelo mecanismo do Fundo de Desenvolvimento das Atividades Portuárias $(\text { Fundap })^{5}$; a extração de petróleo e gás; a evolução dos arranjos produtivos importantes para a economia local, como o de alimentos e bebidas, o metal-mecânico, o de rochas ornamentais e o moveleiro; e, por fim, o desempenho do sistema Geres/ Bandes (CAÇADOR, 2008). O destaque para o período ficou a cargo do setor terciário, que elevou sua participação no PIB estadual de 49,8\% em 1990 para 54,1\% em 2000 (CAÇADOR, 2008). Para Mota (2002), o que proporcionou esse salto foi a utilização do Fundap aliada à abertura comercial do país, o que fez com que na década de 1990 houvesse um salto nas importações capixabas e uma elevação no número de empresas importadoras (tradings) com domicílio fiscal no estado 6 .

5 O Fundap é um financiamento para apoio a empresas com sede no Espírito Santo e que realiza operações de comércio exterior tributadas com ICMS no Estado. Ressalta-se que, devido à aprovação do PRS 72/2010 pelo Senado Federal em 24/4/2012, o mecanismo Fundap perdeu atratividade. O projeto unifica em $4 \%$ a alíquota do ICMS cobrada sobre produtos importados em operações interestaduais. A nova regra passou a vigorar em janeiro de 2013, com a proposta de acabar com a "guerra dos portos" nas operações interestaduais com produtos importados. Para maiores informações, ver Felipe (2012).

6 Para maiores esclarecimentos a respeito da importância do mecanismo Fundap para a economia capixaba na década de 1990 e seus desdobramentos, consultar Mota (2002). 
Tabela 1 - Taxa média anual de crescimento do PIB (\%) do ES e do Brasil (1990-2009)

\begin{tabular}{c|cc|cc}
\hline \multirow{2}{*}{ Setores } & \multicolumn{2}{|c|}{$1990-2000$} & \multicolumn{2}{c}{$2000-2009$} \\
\cline { 2 - 5 } & ES & BR & ES & BR \\
\hline Agricultura & 6,1 & 0,7 & 6,9 & 3,7 \\
Indústria & 2,7 & 1,8 & 3,0 & 2,3 \\
Terciário & 4,3 & 1,1 & 6,0 & 3,6 \\
\hline Total & 3,9 & 2,4 & 4,6 & 3,3 \\
\hline
\end{tabular}

Fonte: Caçador (2008) para os anos 1990 e 2000 e Bacen (2013) para os demais anos

De forma geral, os setores marcantes do $3^{\circ}$ ciclo de desenvolvimento capixaba, que ainda se encontra em curso, são: os segmentos de minerais básicos (basicamente pelotização de minério de ferro), metalurgia, papel e celulose, extração de petróleo e gás, alimentos e bebidas, móveis, rochas ornamentais e vestuário e os serviços ligados ao comércio exterior (CAÇADOR, 2008). Apesar de uma relativa diversificação nas atividades em virtude da implantação dos Grandes Projetos na década de 1970, atualmente a economia capixaba ainda permanece dependente da produção de commodities no setor industrial. No setor de serviços, as atividades relacionadas ao comércio exterior representam o ponto mais importante.

A partir de meados da década de 1990, a indústria de petróleo e gás revigorou-se no estado com a descoberta de novas reservas, em grande parte realizadas pela Petróleos Brasileiros S/A (Petrobras) (CAÇADOR, 2008). Atualmente, o estado encontra-se em segundo lugar na produção nacional de petróleo, ficando atrás somente do estado do Rio de Janeiro. Segundo dados da Agência Nacional de Petróleo a respeito das reservas provadas, em 2011 o estado possuía 1,305 bilhões de barris localizados em mar.

Consoante com Caçador (2008), a economia capixaba continua dependente da produção de commodities voltadas para o comércio exterior e, mais recentemente, o setor de petróleo e o da construção civil passaram a ocupar lugar de destaque na produção capixaba. A construção civil tem impactado no setor de serviços, no de atividades imobiliárias, no de aluguéis e no de serviços prestados. Toda a análise apresentada pode ser demonstrada no Gráfico 1, que revela a composição setorial do PIB do Espírito Santo entre 1990-2009, período no qual o crescimento do setor terciário e industrial foi expressivo. 


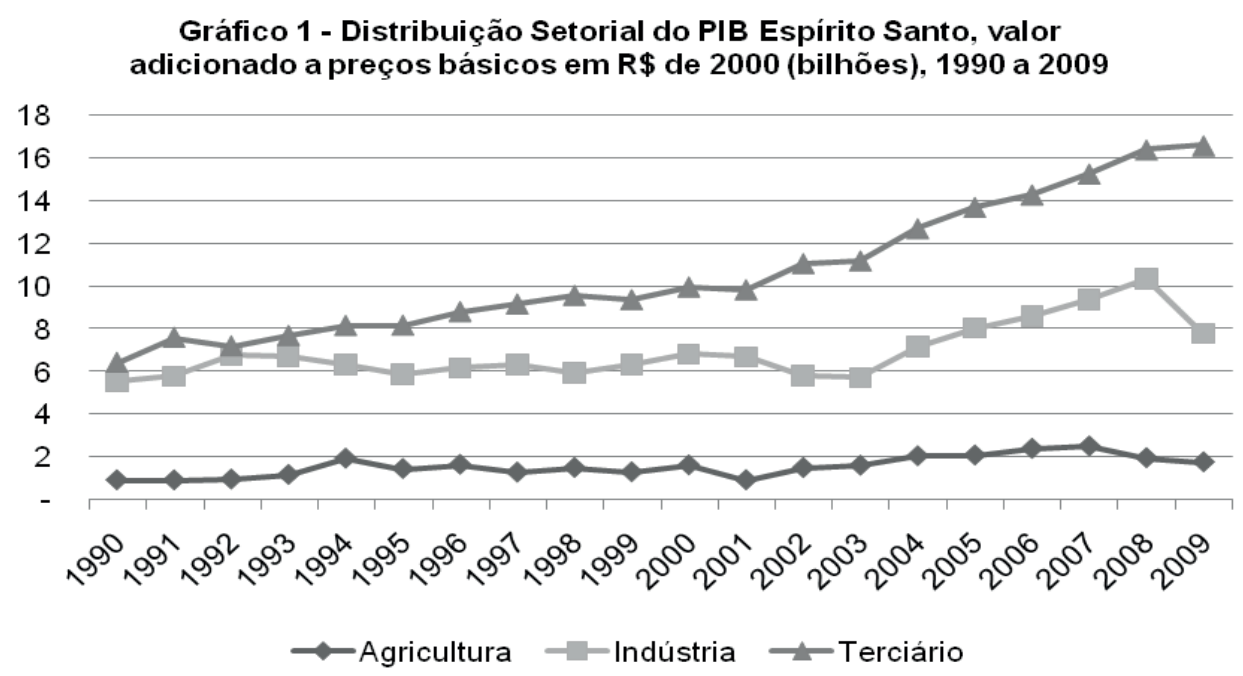

Fonte: elaboração própria com base no IPEA (2013)

Em termos socioeconômicos, a título de exemplificação, em 1970, o Índice de Desenvolvimento Humano (IDH) do estado era de 0,415, e em 2005 saltou para 0,802 , sendo considerado alto (IDH acima de 0,8 ), colocando o estado na $7^{\mathrm{a}}$ posição entre todas as unidades da federação.

Segundo dados do último censo realizado pelo Instituto Brasileiro de Geografia e Estatística (IBGE) relativo a 2010, a população total do estado é de 3,51 milhões de pessoas e, desse total, cerca de $83,40 \%$ residem em áreas urbanas. Em torno de 1,68 milhões de habitantes vivem na RMGV, ou seja, $48 \%$ da população total do estado. Esse processo iniciou-se na década de $1950 \mathrm{com}$ a crise da economia cafeeira e intensificou-se a partir de meados dos anos 1970, com a chegada dos grandes projetos. A população economicamente ativa corresponde a 1,51 milhões de pessoas, com destaque para a taxa de desocupação (porcentagem das pessoas desocupadas em relação às pessoas economicamente ativas) que, de 2000 até 2010, passou de $13,40 \%$ para $7,28 \%$, apresentando uma queda de $45,67 \%$.

Ressalta-se que existem dois trabalhos de referência a respeito dos desdobramentos da economia capixaba após os anos 1990 que apresentam visões distintas sobre os caminhos que a economia local percorreu nessas últimas décadas. Um deles é Caçador (2008), que afirma que o $3^{\circ}$ ciclo de desenvolvimento econômico do Espírito Santo é caracterizado por uma "diversificação concentradora", no sentido de que a economia local aumentou sua diversificação com base na ampliação das atividades produtivas mais relevantes como serviços ligados ao comércio exterior, alimentos e bebidas, o setor metal-mecânico, móveis, rochas ornamentais, vestuário, construção civil e petróleo e gás. Entretanto, o autor ratifica que houve concentração em função da ampliação da importância dos Grandes Projetos e da 
indústria do petróleo e gás, que produzem basicamente commodities.

Por outro lado, Mota (2002) argumenta que a principal característica no pós-90 foi o aumento da heterogeneidade da economia estadual. De um lado, os Grandes Projetos e as companhias importadoras (tradings) inseridos no processo de globalização da economia mundial e atrelados a uma maior internacionalização da economia brasileira, e, por outro, o desenvolvimento das pequenas e médias empresas, que têm seu dinamismo ligado ao mercado interno do país. Ou seja, o processo de aumento da heterogeneidade pode ser resumido à dicotomia entre mercado interno e mercado externo.

De forma geral, a economia capixaba, em torno de 40 anos, realizou seu processo de industrialização e urbanização, entretanto são notáveis as fragilidades estruturais desse processo como, por exemplo, a restrita diversificação produtiva, com os principais setores baseados na produção de commodities e as pequenas e médias empresas apresentando níveis restritos de competitividade (MORANDI et al., 2011)

Além disso, o processo de ocupação em torno dos grandes centros, aliado à concentração de renda, é tido como o principal impacto negativo do desenvolvimento econômico capixaba. E, ao contrário do que tem acontecido em outras metrópoles do Sudeste, nas quais o processo de metropolização da capital promoveu uma "dispersão concentrada", no Espírito Santo esse processo ficou limitado a Vitória e aos municípios vizinhos, indicando que as atividades mais dinâmicas do estado (mineração, siderurgia, papel e celulose e comércio internacional) possuem limitados encadeamentos a montante e a jusante (MORANDI et al., 2011).

\section{A Matriz de Insumo-Produto}

Esta seção abordará a teoria de insumo-produto, desenvolvida inicialmente por Wassily Leontief, e suas respectivas aplicações em economia com vistas a servir de base metodológica para o estudo de impacto econômico que será realizado.

\subsection{O Modelo de Insumo-Produto}

Elaborada apoiada nos dados do Sistema de Contas Nacionais, a Matriz de Insumo-Produto (MIP) apresenta o fluxo de bens e serviços entre os setores da economia, sendo um quadro de dupla entrada que registra, por um lado, os insumos utilizados pelas diversas atividades econômicas e, por outro, o destino da produção, demonstrando as relações de interdependência entre os setores e permitindo avaliar os impactos de variações na demanda final dos produtos (KURESKI, NUÑEZ e RODRIGUES, 2007). Para Leontief (1964), o ponto central da análise de insumo-produto é a ideia de que há uma relação fundamental entre o volume de produto de uma indústria e a quantidade de insumo que esta absorve. 
No modelo são adotadas duas hipóteses, resumidas por Guilhoto (2011): a) homogeneidade, não se considera diferenciação de produtos, havendo razão fixa de insumos (tecnologias fixas no processo produtivo), com rendimento constante de escala (apenas uma tecnologia é empregada na produção de um produto); e b) proporcionalidade, os insumos consumidos em cada atividade são função somente do nível de produção da respectiva atividade.

O modelo de insumo-produto, representado na Figura 1, é dividido em setores $(1,2, \ldots, n)$, obtendo para cada um deles a demanda intermediária $\left(\sum x_{i j}\right)$, a demanda final $\left(Y_{n}\right)$ e o valor bruto da produção $\left(X_{n}\right)$. A diferença entre o valor bruto da produção e o consumo intermediário resulta no valor adicionado, que é usado como a remuneração dos fatores de produção como salários, aluguéis, lucros e juros (KURESKI, NUNEZ e RODRIGUES, 2007).

Figura 1 - Fluxo de bens por setores de origem e destino

\begin{tabular}{|c|c|c|c|c|c|c|}
\hline \multirow[b]{2}{*}{ ATIVIDADES } & \multicolumn{4}{|c|}{ DEMANDA INTERMEDIÁRIA } & \multirow{2}{*}{$\begin{array}{c}\text { Total da } \\
\text { Demanda } \\
\text { Final }\end{array}$} & \multirow{2}{*}{$\begin{array}{l}\text { Valor Bruto da } \\
\text { Produção }\end{array}$} \\
\hline & Setor 1 & Setor 2 & $\ldots$ & Setor $n$ & & \\
\hline Setor 1 & $x_{11}$ & $x_{12}$ & $\ldots$ & $x_{1 n}$ & $Y_{1}$ & $X_{1}$ \\
\hline Setor 2 & $x_{21}$ & $x_{22}$ & $\cdots$ & $x_{2 n}$ & $Y_{2}$ & $X_{2}$ \\
\hline$\vdots$ & $\vdots$ & $\vdots$ & $\vdots$ & $\vdots$ & $\vdots$ & $\vdots$ \\
\hline Setor $n$ & $x_{n 1}$ & $x_{n 2}$ & $\cdots$ & $x_{n n}$ & $Y_{n}$ & $X_{n}$ \\
\hline Valor Adicionado & $Z_{1}$ & $Z_{2}$ & $\cdots$ & $Z_{n}$ & & \\
\hline Valor Bruto da Produção & $X_{1}$ & $X_{2}$ & $\cdots$ & $X_{n}$ & & \\
\hline
\end{tabular}

Fonte: Kureski, Nuñes e Rodrigues (2007)

Pelo cálculo dos coeficientes técnicos, que são as necessidades diretas de insumos dos diversos setores (relações intra e interindustriais diretas) e da determinação dos efeitos diretos e indiretos resultantes do aumento da demanda final, tem-se a equação básica do modelo

$$
X=(I-A)^{-1} Y
$$

Em que:

$X=$ valor bruto da produção ${ }^{7}$;

$(I-A)^{-1}=$ matriz de Leontief;

$Y=$ demanda final.

Para avaliar os reais impactos sobre a economia determinados pela Matriz Insumo-Produto, é necessário identificar e quantificar os efeitos multiplicadores de impacto setorial de cada atividade econômica. Os dois multiplicadores principais são:

7 Valor bruto da produção representa toda a receita bruta gerada na economia, ou seja, compreende a totalidade das transferências realizadas, mais as vendas efetuadas, mais as variações dos estoques. 
i) multiplicador direto: mede o impacto de um aumento unitário da demanda final de uma determinada atividade sobre uma variável de renda, considerando apenas as atividades que fornecem insumos diretamente para essa atividade;

ii) multiplicador total (direto mais indireto): mede o impacto de um aumento unitário da demanda final de uma determinada atividade sobre uma variável de renda, considerando todas as atividades que fornecem insumos, direta e indiretamente a essa atividade.

Ao se aplicar um valor de choque pertinente à alteração das demandas, observa-se o impacto causado pelos efeitos multiplicadores dos setores.

\subsection{Modelo MIP para o Espírito Santo}

A Matriz Insumo-Produto do Espírito Santo (Mipes) de 2003 procura analisar a relação inter-regional do estado e é dividida em 36 setores.

Tabela 2 - Estrutura Setorial e Multiplicadores da Mipes

\begin{tabular}{l|c|c|c|c|c}
\hline \multirow{2}{*}{\multicolumn{1}{c|}{ Setores }} & \multicolumn{3}{c|}{ Multiplicador } & \multicolumn{2}{c}{$\begin{array}{c}\text { Participação no } \\
\text { Multiplicador }\end{array}$} \\
\cline { 2 - 6 } & Total & Local & $\begin{array}{c}\text { Inter-Re- } \\
\text { gional }\end{array}$ & Local & $\begin{array}{c}\text { Inter-Re- } \\
\text { gional }\end{array}$ \\
\hline Agropecuária & 1,928 & 1,126 & 0,802 & $58 \%$ & $42 \%$ \\
Extrativa mineral & 2,000 & 1,274 & 0,726 & $64 \%$ & $36 \%$ \\
Extração de petróleo e gás & 1,387 & 1,096 & 0,291 & $79 \%$ & $21 \%$ \\
Produtos de minerais não metálicos & 2,093 & 1,367 & 0,725 & $65 \%$ & $35 \%$ \\
Metalurgia básica & 2,470 & 1,376 & 1,094 & $56 \%$ & $44 \%$ \\
Outros metalúrgicos & 2,506 & 1,414 & 1,093 & $56 \%$ & $44 \%$ \\
Máquinas e equipamentos & 1,875 & 1,244 & 0,632 & $66 \%$ & $34 \%$ \\
Material elétrico & 2,435 & 1,399 & 1,036 & $57 \%$ & $43 \%$ \\
Equipamentos eletrônicos & 1,885 & 1,194 & 0,691 & $63 \%$ & $37 \%$ \\
Automóveis, caminhões e ônibus & 2,361 & 1,211 & 1,150 & $51 \%$ & $49 \%$ \\
Autopeças e outros veículos & 2,414 & 1,353 & 1,061 & $56 \%$ & $44 \%$ \\
Celulose, papel e gráfica & 2,109 & 1,403 & 0,706 & $67 \%$ & $33 \%$ \\
Produtos da borracha e artigos plásticos & 2,192 & 1,283 & 0,908 & $59 \%$ & $41 \%$ \\
Elementos químicos, farmacêuticos e vete- & 2,175 & 1,208 & 0,968 & $56 \%$ & $44 \%$ \\
rinários & 2,053 & 1,452 & 0,601 & $71 \%$ & $29 \%$ \\
Refino do petróleo & 2,637 & 1,167 & 1,470 & $44 \%$ & $56 \%$ \\
Têxtil & & & & & \\
& & & & &
\end{tabular}


(Continuação)

\begin{tabular}{l|ccc|cc} 
Vestuário & 2,366 & 1,152 & 1,214 & $49 \%$ & $51 \%$ \\
Calçados & 2,146 & 1,182 & 0,963 & $55 \%$ & $45 \%$ \\
Indústria alimentícia, bebidas, fumo e bio- & 2,556 & 1,260 & 1,295 & $49 \%$ & $51 \%$ \\
combustíveis & 2,072 & 1,261 & 0,811 & $61 \%$ & $39 \%$ \\
Madeira, mobiliário e indústrias diversas & 1,891 & 1,474 & 0,417 & $78 \%$ & $22 \%$ \\
Energia elétrica (produção e distribuição) & 2,055 & 1,337 & 0,718 & $65 \%$ & $35 \%$ \\
Gás encanado (produção e distribuição) & 1,681 & 1,403 & 0,278 & $83 \%$ & $17 \%$ \\
Água e saneamento & 1,908 & 1,307 & 0,601 & $68 \%$ & $32 \%$ \\
Construção civil & 1,876 & 1,315 & 0,562 & $70 \%$ & $30 \%$ \\
Comércio & 2,199 & 1,358 & 0,841 & $62 \%$ & $38 \%$ \\
Serviços de transporte rodoviário & 2,178 & 1,321 & 0,857 & $61 \%$ & $39 \%$ \\
Serviços de transporte ferroviário & 2,302 & 1,381 & 0,921 & $60 \%$ & $40 \%$ \\
Serviços de transporte aéreo & 1,776 & 1,205 & 0,571 & $68 \%$ & $32 \%$ \\
Serviços de transporte - outros modais & 1,584 & 1,206 & 0,378 & $76 \%$ & $24 \%$ \\
Serviços de comunicações & 1,456 & 1,175 & 0,281 & $81 \%$ & $19 \%$ \\
Instituições financeiras & 1,910 & 1,163 & 0,747 & $61 \%$ & $39 \%$ \\
Serviços prestados às famílias & 1,569 & 1,231 & 0,338 & $78 \%$ & $22 \%$ \\
Serviços prestados às empresas & 1,260 & 1,068 & 0,192 & $85 \%$ & $15 \%$ \\
Aluguel de imóveis & 1,504 & 1,211 & 0,293 & $80 \%$ & $20 \%$ \\
Administração pública & 1,150 & 1,046 & 0,104 & $91 \%$ & $9 \%$ \\
Serviços privados não mercantis & Fon \\
\hline
\end{tabular}

Fonte: MIP

$\mathrm{O} 3^{\circ}$ ciclo de desenvolvimento da economia capixaba continua em curso, com destaque para os seguintes setores: minerais básicos (principalmente pelotização de minério de ferro), metalurgia, papel e celulose, extração de petróleo e gás, alimentos e bebidas, móveis e rochas ornamentais, vestuário e serviços. A Tabela 2 apresenta os coeficientes técnicos dos 36 setores da Mipes e o destaque fica justamente para os setores que compóem o curso recente de desenvolvimento do estado. Apesar de alguns deles não apresentarem o maior coeficiente total de impacto, em termos de coeficientes locais, os números são bem relevantes e importantes para a economia capixaba na medida em que os coeficientes locais determinam os impactos ocorridos que permanecem dentro do estado.

Os coeficientes técnicos refletem o quanto cada setor necessita de produto de outro setor. A partir do conhecimento deles é possível realizar previsões de produção, bem como verificar o impacto de diversas alternativas de políticas econômicas sobre a atividade produtiva. Esses coeficientes refletem a estrutura da economia e não apresentam mudanças significativas a curto e médio prazos, 
o que os tornam importantes indicadores para previsões (LOPES e VASCONCELLOS, 2009).

Com relação à economia capixaba recente, consoante Gráfico 2, os setores mais importantes e multiplicadores em destaque são: metalurgia básica; outros metalúrgicos; papel, celulose e gráfica; construção civil; madeira, mobiliário e indústrias diversas; gás encanado; refino de petróleo; extração mineral; comércio; extração de petróleo e gás e produtos de minerais não metálicos. Basicamente, como exposto anteriormente, são os setores que compóem o $3^{\circ}$ ciclo de desenvolvimento da economia capixaba.

Gráfico 2: Multiplicadores de impacto dos setores mais importantes do Espírito Santo

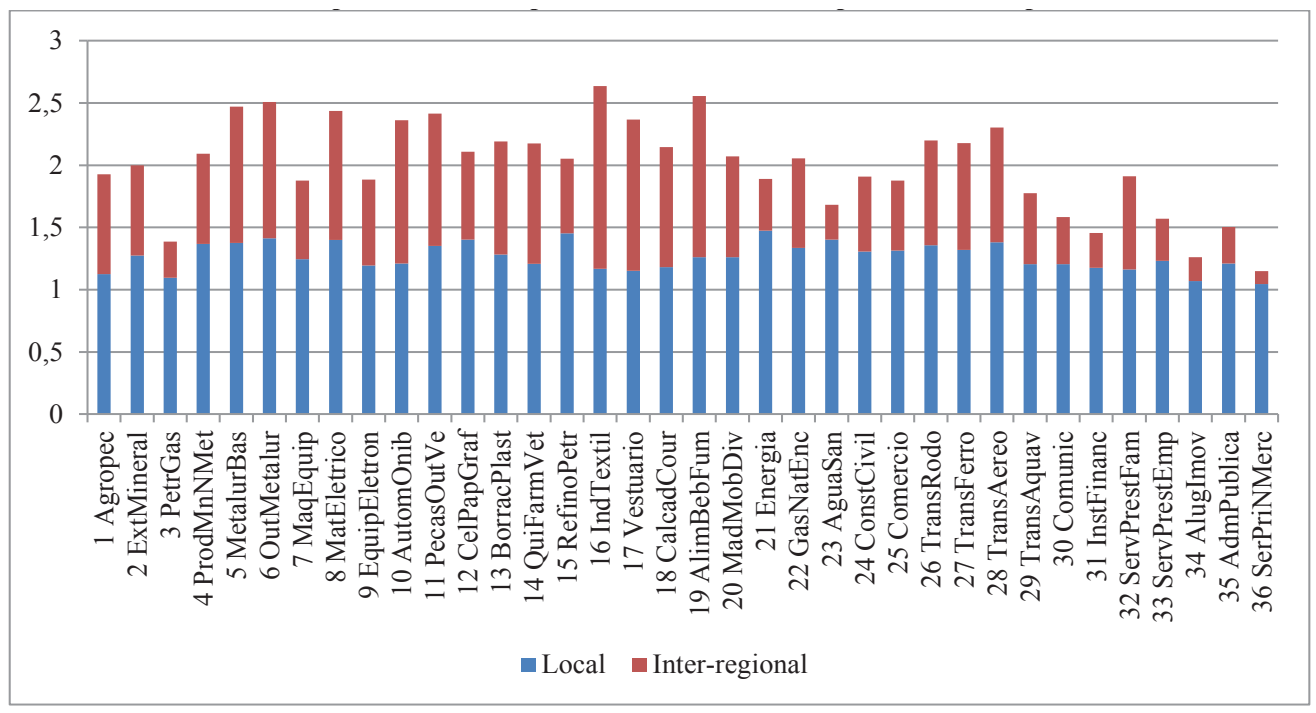

Fonte: MIP

\section{Estudo do Impacto Econômico dos Investimentos para o Espírito Santo 2011-2016}

Nesta seção, será realizado um estudo de impacto econômico por intermédio da Matriz de Insumo-Produto do Espírito Santo em relação aos investimentos previstos entre 2011 e 2016, com ênfase nos setores de infraestrutura e da indústria, bem como serão apresentados os resultados obtidos. Também será demonstrada a base de dados utilizada e uma breve descrição a respeito dos principais investimentos e setores contemplados. 


\subsection{Base de dados}

A pesquisa "Investimentos anunciados para o Espírito Santo 2011-2016" consiste em um levantamento sistemático de intenções de investimentos relacionadas ao estado do Espírito Santo ao longo de um período de cinco anos. Os investimentos podem ser tanto de origem pública quanto privada, tendo como ponto de partida investimentos com valores maiores ou iguais a $\mathrm{R} \$ 1$ milhão. As fontes primárias de dados são os levantamentos diretos realizados pelo Instituto Jones dos Santos Neves. Os projetos de investimentos contidos nessa pesquisa são oriundos basicamente de anúncios de investimentos divulgados pelos principais meios de comunicação em níveis nacional e estadual.

A Tabela 3 evidencia os principais investimentos que serão realizados no período 2011-2016, e apresenta o panorama geral dos investimentos e principais setores contemplados em termos agregados.

Segundo dados do Instituto Jones dos Santos Neves (2012), entre 2011 e 2016, a economia capixaba deve receber investimentos superiores a $\mathrm{R} \$ 100$ bilhões, o maior volume já identificado para o estado, distribuídos entre 1.373 projetos com valor médio de $\mathrm{R} \$ 73,3$ milhões. Em termos agregados, o setor de energia é o que deve receber o maior volume de recursos $(40,3 \%)$, seguido do setor de indústria $(32,5 \%)$ e do setor de comércio, serviço e lazer $(7,3 \%)$. No que diz respeito à distribuição regional dos investimentos, a região litoral sul e a região metropolitana receberão $45,5 \%$ e $25,2 \%$ dos investimentos, respectivamente.

Tabela 3 - Investimentos, segundo setores, por número de projetos e valor total, em milhões (2011-2016)

\begin{tabular}{l|rr|rr|r}
\hline \multicolumn{1}{c|}{ Setores } & Projetos & \% & $\begin{array}{l}\text { Investi- } \\
\text { mentos }\end{array}$ & \% & $\begin{array}{c}\text { Valor } \\
\text { Médio }\end{array}$ \\
\hline Infraestrutura & $\mathbf{3 4 7}$ & $\mathbf{2 5 , 3}$ & $\mathbf{5 3 . 2 1 4 , 3}$ & $\mathbf{5 2 , 8}$ & $\mathbf{1 5 3 , 4}$ \\
Energia & 82 & 6,0 & $40.577,3$ & 40,3 & 494,8 \\
Porto, aeroporto e armazenagem & 67 & 4,9 & $6.544,5$ & 6,5 & 97,7 \\
Transporte & 198 & 14,4 & $6.092,5$ & 6,1 & 30,8 \\
Indústria & $\mathbf{8 2}$ & $\mathbf{6 , 0}$ & $\mathbf{3 2 . 7 2 4 , 8}$ & $\mathbf{3 2 , 5}$ & $\mathbf{3 9 9 , 1}$ \\
Comércio, serviço e lazer & $\mathbf{1 6 0}$ & $\mathbf{1 1 , 7}$ & $\mathbf{7 . 3 9 3 , 8}$ & $\mathbf{7 , 3}$ & $\mathbf{4 6 , 2}$ \\
Outros serviços & $\mathbf{7 8 4}$ & $\mathbf{5 7 , 1}$ & $\mathbf{7 . 3 5 8 , 5}$ & $\mathbf{7 , 3}$ & $\mathbf{9 , 4}$ \\
Saneamento e Urbanismo & 421 & 30,7 & $3.888,6$ & 3,9 & 9,2 \\
Educação & 187 & 13,6 & $1.232,4$ & 1,2 & 6,6 \\
Meio ambiente & 8 & 0,6 & 808,4 & 0,8 & 101,1 \\
Saúde & 105 & 7,6 & 851,0 & 0,8 & 8,1 \\
Segurança Pública & 63 & 4,6 & 578,1 & 0,6 & 9,2 \\
\hline Total & $\mathbf{1 . 3 7 3}$ & $\mathbf{1 0 0}$ & $\mathbf{1 0 0 . 6 9 1 , 4}$ & $\mathbf{1 0 0}$ & $\mathbf{7 3 , 3}$ \\
\hline
\end{tabular}

Fonte: IJSN (2012) 
$\mathrm{Na}$ Tabela 4, constata-se que $\mathrm{R} \$ 91,6$ bilhões serão destinados às dez principais atividades, representando $90,9 \%$ do total dos investimentos. Nessa perspectiva, a principal atividade a receber investimentos é a de extração de petróleo e gás natural, com aportes de R $\$ 26,8$ bilhões. Esses investimentos destinam-se à prospecção, ao processamento e ao desenvolvimento da produção da Bacia do Espírito Santo e da Bacia de Campos, além dos projetos implantados em terra (IJSN, 2012). A metalurgia ocupa o segundo lugar, com R $\$ 12,4$ bilhões, destinados basicamente à implantação no estado de uma nova planta siderúrgica (Companhia Siderúrgica UBU - CSU/Vale) no município de Anchieta, e à modernização e ampliação das plantas já existentes no setor (IJSN, 2012).

Em seguida, tem-se a extração de minerais metálicos com investimentos previstos da ordem de R \$11,4 bilhões do total, voltados para a instalação de novas plantas pelotizadoras ( $8^{\mathrm{a}}$ usina da Vale e a $4^{\mathrm{a}}$ usina da Samarco Mineração), bem como a implantação da Ferrous Resources do Brasil, no município de Presidente Kennedy, que consiste em um complexo de pelotização associado a um porto de águas profundas destinado ao escoamento da produção (ISJN, 2012). Já o setor eletricidade, gás e outras utilidades representa 10,6\% dos investimentos. Basicamente, os projetos dessa área concentram-se na transmissão e na geração de energia elétrica pelas usinas termelétricas e hidrelétricas (IJSN, 2012). E, por fim, a atividade de fabricação de produtos químicos representa 7,6\% ou R $\$ 7,7$ bilhões do total, composta por três atividades, com destaque para o complexo gás-químico (Petrobras) previsto para ser instalado no município de Linhares, no norte do estado (IJSN, 2012). Ainda em relação à Tabela 4 , nota-se a concentração dos investimentos em poucas atividades produtivas, o que corrobora a tese de Caçador (2008) a respeito da "diversificação concentradora" na economia capixaba.

Tabela 4 - Principais atividades receptoras de investimentos no Espírito Santo 2011-2016

\begin{tabular}{clrc}
\hline CNAE & Classificação & R\$ milhões & $\mathbf{( \% )}$ \\
\hline 06 & Extração de petróleo e gás natural & $26.829,50$ & 26,6 \\
24 & Metalurgia & $12.365,60$ & 12,3 \\
07 & Extração de minerais metálicos & $11.379,20$ & 11,3 \\
35 & Eletricidade, gás e outras utilidades & $10.636,50$ & 10,6 \\
20 & Fabricação de produtos químicos & $7.655,00$ & 7,6 \\
42 & Obras de infraestrutura & $6.953,90$ & 6,9 \\
41 & Construção de edifícios & $6.715,50$ & 6,7 \\
52 & Armazenamento e atividades auxiliares dos transportes & $4.348,10$ & 4,3 \\
49 & Transporte terrestre & $2.840,90$ & 2,8
\end{tabular}




\section{(Continuação)}

30 Fabricação de outros equipamentos de transporte, exceto veículos automotores

11 Fabricação de bebidas

$$
1.837,80 \quad 1,8
$$

85 Educação

$1.259,80 \quad 1,3$

36 Captação, tratamento e distribuição de água

$1.187,40 \quad 1,2$

86 Atividades de atenção à saúde humana

$953,40 \quad 0,9$

17 Fabricação de celulose, papel e produtos de papel

84 Administração pública, defesa e seguridade social

27 Fabricação de máquinas, aparelhos e materiais elétricos

19 Fabricação de coque, de produtos derivados do petróleo e de biocombustíveis

\subsection{Estimativas de impacto}

Nas estimativas, considerou-se que a estrutura econômica do Espírito Santo permaneceu estática desde 2003, sendo as oscilações oriundas apenas dos impactos diretos e indiretos dos investimentos anunciados para o Espírito Santo 2011-2016. Ressalta-se, ainda, que para as simulações com base na Mipes, os valores dos projetos acima descritos foram deflacionados pelo deflator implícito da FBCF para dezembro de 2003, que representa melhor a variação de preços desse componente da demanda final. Além disso, foram deduzidos os impostos e as importações, o que reduz o montante total em aproximadamente $19 \%$. Cabe ressaltar, consoante Tabela 4, que o setor "Outros" não faz parte das estimativas, em função desse setor não apresentar uma correspondência direta com os setores da Mipes.

Os recursos previstos para investimentos não necessariamente representam choques favoráveis de demanda nos setores da Tabela 4, mas sim naqueles setores listados no vetor de absorção de investimentos de cada setor que fornecem insumos que contribuem para a sua formação bruta de capital fixo (FBCF). Como cada setor apresenta um comportamento diferenciado de alocação dos recursos para investimentos, os choques para a simulação foram aplicados nos setores da matriz de acordo a Unidade Padrão de Investimento (UPI) da Matriz de Absorção de Investimentos (MAI), procedimento comum adotado nos trabalhos sobre impactos de investimentos com MIP, a exemplo de Freitas (2009) e Miguez et al. (2014). 
Tabela 5 - Distribuição dos investimentos seguindo a UPI da MAI (R\$ milhões)

\begin{tabular}{|c|c|c|c|c|c|}
\hline Setor & Sigla & Nome & Valor & ES & $\begin{array}{c}\text { Resto do } \\
\text { BR }\end{array}$ \\
\hline 6 & OutMetalur & Outros metalúrgicos & $5.690,33$ & 519,42 & $5.170,90$ \\
\hline 7 & MaqEquip & Máquinas e equipamentos & $20.312,38$ & 180,25 & $20.132,12$ \\
\hline 9 & EquipEletron & Equipamentos eletrônicos & $13.067,16$ & 0,24 & $13.066,92$ \\
\hline 10 & AutomOnib & $\begin{array}{c}\text { Automóveis, caminhões e } \\
\text { ônibus }\end{array}$ & $5.041,04$ & 0,09 & $5.040,93$ \\
\hline 11 & PecasOutVe & Autopeças e outros veículos & $1.462,92$ & 0,02 & $1.462,89$ \\
\hline 20 & MadMobDiv & $\begin{array}{l}\text { Madeira, mobiliário e } \\
\text { indústrias diversas }\end{array}$ & $8.527,28$ & 0,16 & $8.527,12$ \\
\hline 24 & ConstCivil & Construção civil & $11.440,80$ & 235,27 & $11.205,53$ \\
\hline 25 & Comercio & Comércio & $10.147,25$ & 183,24 & $9.964,00$ \\
\hline 26 & TransRodo & $\begin{array}{l}\text { Serviços de transporte } \\
\text { rodoviário }\end{array}$ & $1.634,73$ & 85,62 & $1.549,10$ \\
\hline 33 & $\begin{array}{l}\text { ServPres- } \\
\text { tEmp }\end{array}$ & $\begin{array}{c}\text { Serviços prestados às } \\
\text { empresas }\end{array}$ & 703,95 & 22,22 & 681,72 \\
\hline 34 & AlugImov & Aluguel de imóveis & $1.837,19$ & 23,39 & $1.813,78$ \\
\hline TOTAL & & & $79.865,03$ & $1.249,974$ & $78.615,05$ \\
\hline
\end{tabular}

Fonte: Elaboração própria.

A Tabela 6 apresenta o resultado dos impactos gerados, em termos de valor bruto da produção, na economia capixaba e no Brasil pelos investimentos anunciados. Ao utilizar os multiplicadores totais de produção para medir os impactos gerados na economia capixaba pelos investimentos anunciados, faz-se necessário atentar para o tamanho do investimento em relação à capacidade produtiva do setor. Conforme os resultados apresentados pela Tabela 6, o setor de equipamentos eletrônicos, por exemplo, deverá aumentar 53,94\%. O possível percentual de crescimento muito elevado em função dos investimentos que serão recebidos pode ser explicado em função da pouca expressividade desses setores na economia capixaba. Como a base produtiva desses setores é pequena na economia do estado, depara-se com um problema estatístico de se trabalhar com números muito pequenos relacionados à base produtiva do setor e números grandes com relação aos investimentos, ou seja, são setores muito pequenos com a expectativa de receber investimentos muito altos.

Dos setores com maior base produtiva no estado, segundo a Tabela 6, Extração Mineral apresenta um crescimento de 1,12\%; Metalurgia Básica, 4,33\%; Papel e Celulose, 2,25\%; Refino de Petróleo, 3,82\%; e Construção Civil, 4,57\%. São os setores que compõem a base da economia do Espírito Santo associados aos setores 
já citados de Energia e Petróleo e Gás. Com relação ao impacto no resto do Brasil, considerando que grande parte dos investimentos será absorvida por outras regiões produtoras, o destaque de crescimento no valor bruto da produção entre 2011-2016 fica nos setores: Equipamentos eletrônicos (56,6\%), Máquinas e equipamentos $(21,7 \%)$, Outros produtos metalúrgicos (12,8\%) e Metalurgia básica (9,2\%). Dos setores que não devem receber investimentos diretos, merecem destaque: Energia $(2,66 \%)$, Gás natural e encanado $(4,03 \%)$ e Instituições financeiras $(2,11 \%)$. O crescimento desses setores, apesar da ausência de investimento direto, demonstra a interdependência entre os setores como preconizado por Leontief.

Dados os vazamentos para outras regiões, essa distribuição dos impactos revela que os investimentos no estado possivelmente terão impactos mais significativos na economia durante a fase de operação do que na de execução.

Tabela 6 - Impacto dos investimentos anunciados no Espírito Santo (2011-2016)

\begin{tabular}{|c|c|c|c|c|c|c|}
\hline \multirow{3}{*}{ Setores } & \multicolumn{5}{|c|}{ Espírito Santo } & \multirow{3}{*}{$\frac{\text { Brasil }}{\operatorname{var} \%}$} \\
\hline & \multirow{2}{*}{$\begin{array}{c}\text { Alteração na } \\
\text { Demanda (R\$ } \\
\text { milhões) }\end{array}$} & \multicolumn{4}{|c|}{ Produção (R\$ milhões) } & \\
\hline & & Base & Impacto & Nova & $\operatorname{var} \%$ & \\
\hline 1 Agropec & 0,000 & 1.912 & 7 & 1.920 & $0,39 \%$ & $0,6 \%$ \\
\hline 2 ExtMineral & 0,000 & 3.307 & 37 & 3.344 & $1,12 \%$ & $3,4 \%$ \\
\hline 3 PetrGas & 0,000 & 4.363 & 136 & 4.499 & $3,12 \%$ & $3,0 \%$ \\
\hline 4 ProdMnNMet & 0,000 & 3.108 & 114 & 3.222 & $3,67 \%$ & $4,5 \%$ \\
\hline 5 MetalurBas & 0,000 & 5.104 & 221 & 5.326 & $4,33 \%$ & $9,2 \%$ \\
\hline 6 OutMetalur & 519,426 & 10.080 & 1.158 & 11.238 & $11,49 \%$ & $12,8 \%$ \\
\hline 7 MaqEquip & 180,256 & 932 & 203 & 1.136 & $21,81 \%$ & $21,7 \%$ \\
\hline 8 MatEletrico & 0,000 & 1 & 0 & 1 & $2,16 \%$ & $3,0 \%$ \\
\hline 9 EquipEletron & 0,241 & 0 & 0 & 1 & $53,94 \%$ & $56,6 \%$ \\
\hline 10 AutomOnib & 0.093 & 1 & 0 & 1 & $9,68 \%$ & $9,7 \%$ \\
\hline 11 PecasOutVe & 0,027 & 1 & 0 & 1 & $5,19 \%$ & $5,6 \%$ \\
\hline 12 CelPapGraf & 0,000 & 7.486 & 169 & 7.655 & $2,25 \%$ & $2,3 \%$ \\
\hline 13 BorracPlast & 0,000 & 462 & 19 & 481 & $4,18 \%$ & $4,6 \%$ \\
\hline 14 QuiFarmVet & 0,000 & 3 & 0 & 3 & $2,24 \%$ & $2,0 \%$ \\
\hline 15 RefinoPetr & 0,000 & 2.495 & 95 & 2.591 & $3,82 \%$ & $3,5 \%$ \\
\hline 16 IndTextil & 0,000 & 1 & 0 & 1 & $0,92 \%$ & $1,0 \%$ \\
\hline 17 Vestuario & 0,000 & 547 & 0 & 547 & $0,05 \%$ & $0,1 \%$ \\
\hline 18 CalcadCour & 0,000 & 0 & 0 & 0 & $0,14 \%$ & $0,2 \%$ \\
\hline 19 AlimBebFum & 0,000 & 3.360 & 3 & 3.363 & $0,09 \%$ & $0,1 \%$ \\
\hline
\end{tabular}


(Continuação)

\begin{tabular}{lcccccc}
20 MadMobDiv & 0,161 & 1 & 0 & 2 & $13,02 \%$ & $14,5 \%$ \\
21 Energia & 0,000 & 665 & 18 & 682 & $2,66 \%$ & $2,2 \%$ \\
22 GasNatEnc & 0,000 & 0 & 0 & 0 & $4,03 \%$ & $4,0 \%$ \\
23 AguaSan & 0,000 & 1.070 & 26 & 1.096 & $2,41 \%$ & $2,2 \%$ \\
24 ConstCivil & 235,273 & 5.598 & 256 & 5.854 & $4,57 \%$ & $4,5 \%$ \\
25 Comercio & 183,246 & 5.149 & 281 & 5.430 & $5,46 \%$ & $5,5 \%$ \\
26 TransRodo & 85,628 & 4.393 & 187 & 4.580 & $4,25 \%$ & $4,3 \%$ \\
27 TransFerro & 0,000 & 165 & 4 & 169 & $2,49 \%$ & $1,9 \%$ \\
28 TransAereo & 0,000 & 301 & 3 & 305 & $1,04 \%$ & $1,1 \%$ \\
29 TransAquav & 0,000 & 435 & 12 & 447 & $2,72 \%$ & $2,7 \%$ \\
30 Comunic & 0,000 & 897 & 19 & 916 & $2,08 \%$ & $2,0 \%$ \\
31 InstFinanc & 0,000 & 4 & 0 & 4 & $2,11 \%$ & $2,9 \%$ \\
32 ServPrestFam & 0,000 & 3.546 & 4 & 3.550 & $0,11 \%$ & $0,2 \%$ \\
33 ServPrestEmp & 22,225 & 4.743 & 131 & 4.874 & $2,77 \%$ & $3,1 \%$ \\
34 AlugImov & 23,398 & 2.819 & 45 & 2.864 & $1,58 \%$ & $1,4 \%$ \\
35 AdmPublica & 0,000 & 8.480 & - & 8.480 & $0,00 \%$ & $0,0 \%$ \\
36 SerPriNMerc & 0,000 & 1 & - & 1 & $0,00 \%$ & $0,0 \%$ \\
\hline
\end{tabular}

Fonte: Elaboração própria.

O resumo dos impactos é apresentado na Tabela 7. Observa-se que apenas $2 \%$ do impacto total ocorrerão na economia do estado, enquanto no resto do país o impacto total será de $98 \%$. Além disso, as alterações na produção do Espírito Santo serão próximas às alterações do Brasil (3,87\% e 3,69\%, respectivamente).

Tabela 7 - Resumo dos impactos

\begin{tabular}{l|c|c|c|c|c|}
\hline \multirow{2}{*}{\multicolumn{1}{c|}{ Produção }} & Base & \multicolumn{2}{c|}{ Impacto } & \multicolumn{2}{c|}{ Nova Produção } \\
\cline { 3 - 6 } & R\$ milhões & R\$ milhões & \multicolumn{1}{c|}{$\%$} & R\$ milhões & var \% \\
\hline Espírito Santo & 81.433 & 3.150 & $2,0 \%$ & 84.583 & $3,87 \%$ \\
Resto do Brasil & 4.194 .511 & 154.788 & $98,0 \%$ & 4.349 .298 & $3,69 \%$ \\
Brasil & 4.275 .944 & 157.938 & $100,0 \%$ & 4.433 .881 & $3,69 \%$ \\
\hline
\end{tabular}

Fonte: Elaboração própria.

Cabe ressaltar que existem muitos investimentos que se encontram em estágio de oportunidades e que em um universo de cinco anos podem apresentar alterações devido à sua magnitude e, também, devido ao cenário internacional, uma vez que muitos deles são voltados ao comércio exterior. É possível que o volume total esteja superestimado para uma economia do tamanho da do Espírito 
Santo em função até mesmo do crescimento que alguns setores podem ter caso esse cenário se concretize ${ }^{8}$.

Figura 1: Mapa dos investimentos previstos de 2011 a 2016

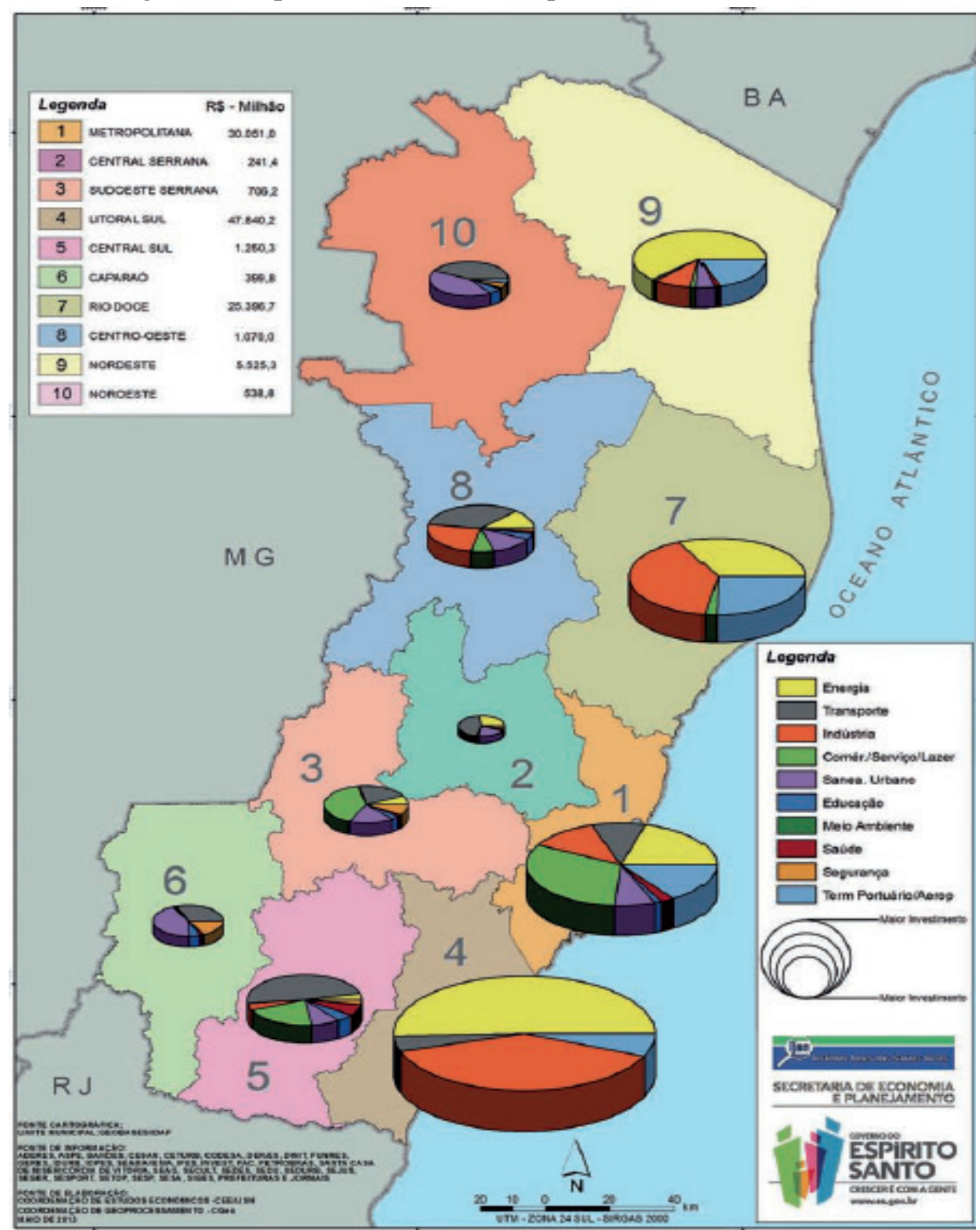

Fonte: IJSN (2012)

8 Além disso, cabe observar que as projeções de um modelo de insumo-produto já são sobrevalorizadas em razão dos preços serem rígidos e, portanto, não captar efeitos de substituição entre os insumos. 
Mesmo que os investimentos representem impactos significativos, as variações provocadas tendem a não alterar o grau de especialização produtiva do estado na produção de commodities. Embora alguns autores como Caçador e Grassi (2009) apontem para um processo de "diversificação concentradora" no estado, ainda há um padrão de concentração setorial (produção de commodities).

A distribuição geográfica dos impactos acima apresentados pode ser observada nos mapas 1 e 2, que mostram a participação dos municípios capixabas na Agropecuária, na Indústria, no Comércio e Serviços e, também, no PIB estadual. Mesmo que a distribuição geográfica seja dos setores, e não dos investimentos específicos, é possível perceber a concentração espacial dos impactos econômicos.

\section{Mapa 1 - Distribuição da Indústria e da Agropecuária no Espírito Santo}

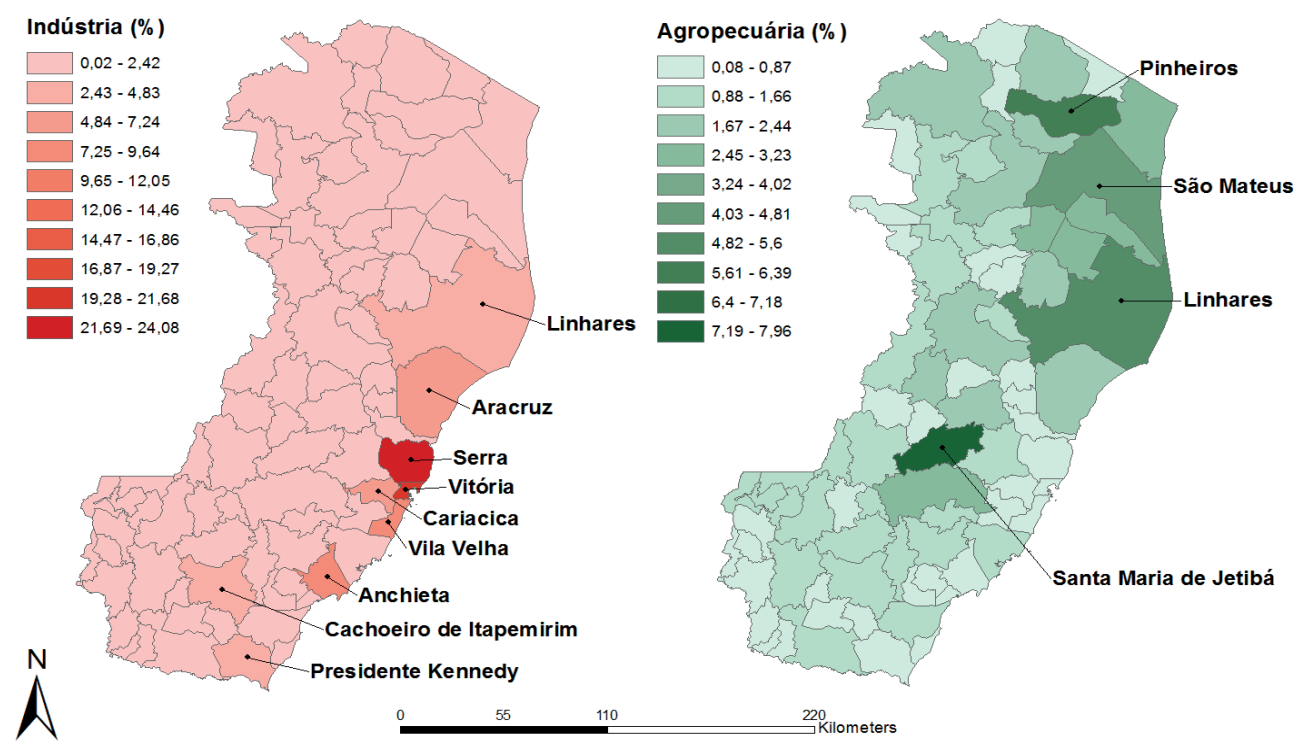

Fonte: Elaboração própria.

Os investimentos em atividades industriais estão relacionados às atividades mais localizadas e, portanto, com maior potencial desequilibrador. A distribuição geográfica (Mapa 1) indica a forte concentração do crescimento econômico na região litorânea do estado. No município de Serra estão presentes muitas atividades industriais, inclusive siderúrgicas, em função de grandes empresas como Vale e ArcelorMittal Tubarão. O município de Aracruz, apesar das atividades agrícolas, conta com a presença da Fibria (antiga Aracruz Celulose). E no litoral sul, destaca-se o município de Anchieta, que possui projetos importantes na área de mineração e 
petróleo (Samarco e Petrobrás). Além dos impactos serem muito localizados, é importante observar que essas atividades (mineração, siderurgia, papel e celulose) possuem limitados encadeamentos a montante e a jusante (MORANDI et al., 2011), inclusive porque a demanda por serviços complexos derivada dessas atividades (serviços às empresas, serviços de informação, intermediação financeira) é suprida por outras capitais do Sudeste, principalmente Rio de Janeiro e São Paulo.

As atividades agropecuárias terão pouco crescimento em razão dos investimentos, de forma que os municípios localizados no interior do estado, com economias baseadas na agricultura muitas vezes familiar e pouco eficiente em termos de produtividade e de geração de renda, quase não serão beneficiados com esse crescimento, possivelmente ampliando a desigualdade entre eles.

Mapa 2 - Distribuição do PIB e do Comércio e Serviços no Espírito Santo

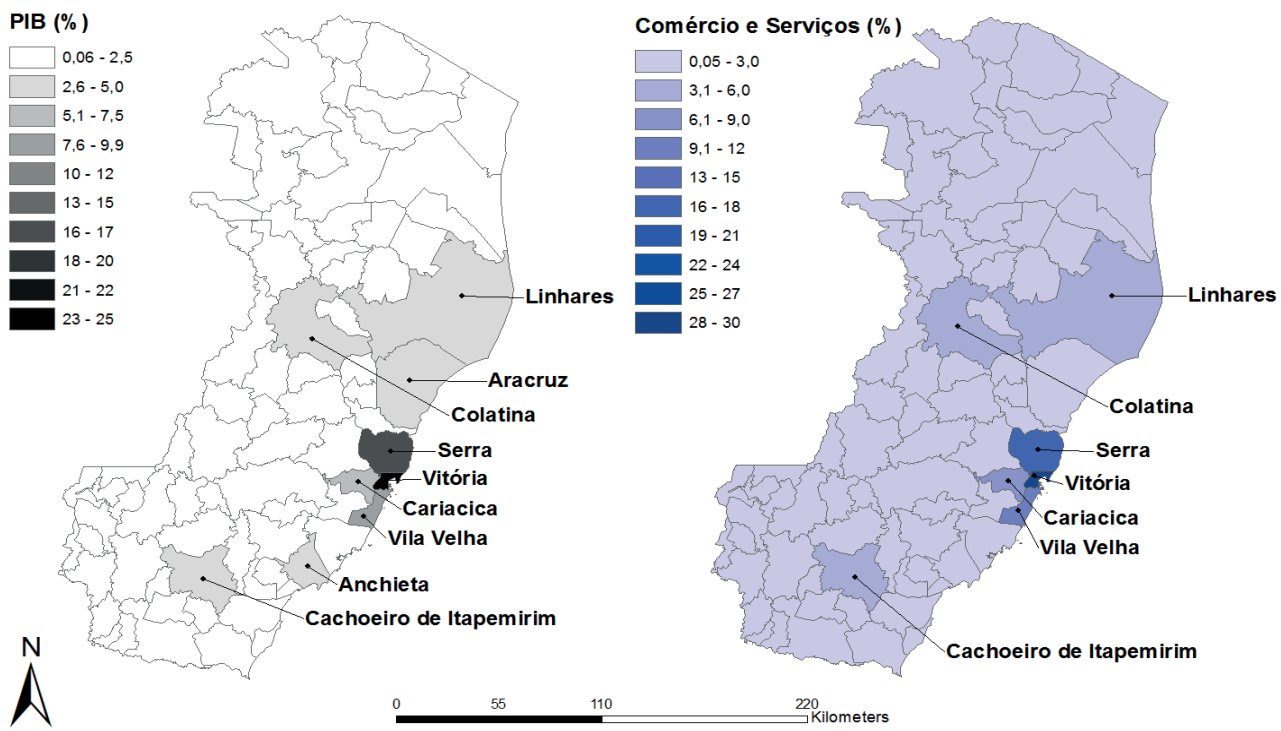

Fonte: Elaboração própria.

Embora o Plano de Desenvolvimento do Estado, denominado Espírito Santo 2025 (ES 2025) ${ }^{9}$, preconize em umas de suas metas a interiorização do desenvolvimento, os investimentos tenderão a beneficiar principalmente o crescimento dos municípios do litoral do Espírito Santo, enquanto os municípios do interior possivelmente continuarão a apresentar um esvaziamento econômico progressivo (via re-

9 Disponível em <http://www.planejamento.es.gov.br>. Acesso em: 14 de abril de 2013. 
dução de suas participações econômicas). Os municípios com melhor desempenho econômico têm se mantido os mesmos nos últimos anos (Região Metropolitana da Grande Vitória, Cachoeiro de Itapemirim, Linhares, Colatina e São Mateus), o que tem gerado um processo de crescimento econômico desigual entre regiões do estado.

Corroborando as ideias de Ruiz e Crocco (2009), como o crescimento econômico no Espírito Santo tem sido acompanhado por uma grande concentração das atividades produtivas em um número restrito de municípios, tem-se no estado a reprodução do padrão locacional da industrialização brasileira (centrípeto, concêntrico e hierárquico) baseado na exploração de vantagens de escala da concentração espacial (economias de aglomeração e urbanização).

\section{Considerações finais}

Neste trabalho, buscou-se mensurar o impacto econômico que os investimentos anunciados para o Espírito Santo entre 2011 e 2016 trarão para a economia capixaba. Para isso, inicialmente foi apresentado o cenário no qual os investimentos ocorrerão, realizando-se, assim, uma contextualização econômica das principais características da economia capixaba e seus ciclos de desenvolvimento. A ferramenta utilizada para o estudo de impacto dos investimentos anunciados foi a Matriz de Insumo-Produto. A principal contribuição desta pesquisa residiu em apontar as distribuições, intensidades e transmissões dos efeitos projetados no sistema produtivo da economia capixaba.

Como resultados desse esforço de pesquisa, ressalta-se que existe ainda uma tendência de concentração dos investimentos nos setores produtores de commodities de exportação, ou seja, nos próximos anos, não há evidências de que ocorrerão mudanças no perfil da economia capixaba, apesar de os investimentos representarem um montante de recursos importante para uma economia do tamanho do Espírito Santo.

Alguns setores apresentaram crescimento, em termos de valor bruto da produção, muito elevado, de certa forma improvável de acontecer. Em função dos resultados apresentados, reforça-se a possibilidade dos investimentos anunciados para o Espírito Santo entre 2011 e 2016 estarem superestimados, ficando como sugestão de pesquisa futura uma investigação mais precisa dessas informações no sentido de tornar as análises posteriores mais realistas. Um problema associado a esse fato é o maior detalhamento das informações que o governo ainda não tornou disponível, ficando essa indicação também como sugestão de estudos futuros.

No geral, para um horizonte de cinco anos, tem-se um volume considerável de recursos que podem ser injetados na economia capixaba, promovendo o crescimento de vários setores. Entretanto, permanece, ainda, a concentração de recursos em setores atualmente tradicionais na economia do estado como metalurgia, petróleo e gás, mineração e energia, demonstrando que a economia estadual ainda 
estará produzindo produtos de baixo conteúdo tecnológico e na maioria dos setores voltados ao mercado externo.

As simulações evidenciam que os desequilíbrios regionais se baseiam principalmente no crescimento dos municípios do litoral e no esvaziamento econômico progressivo do interior do estado. Essa concentração das atividades produtivas em alguns municípios reproduz o padrão locacional da industrialização brasileira baseado na exploração de vantagens de escala da concentração espacial. Os resultados previstos dos investimentos no Espírito Santo parecem ir ao encontro das ideias de polarização de Myrdal, uma vez que os efeitos propulsores (ou de espraiamento) provocados em algumas regiões não serão capazes de reverter o processo de concentração.

\section{Referências Bibliográficas}

BANCO CENTRAL DO BRASIL (BACEN). Diversos dados nacionais, regionais (Espírito Santo e Brasil) para o período 2000-2009. Disponível em: <www. bcb.gov.br>. Acesso em: 10 de março de 2013.

CAÇADOR, Sávio B. Um olhar crítico sobre a evolução da economia capixaba nas últimas décadas: uma análise a partir das teorias de desenvolvimento regional e de estatísticas de inovação. 175 f. Dissertação (mestrado) - Centro de Ciências Jurídicas e Econômicas (CCJE), Universidade Federal do Espírito Santo (UFES), 2008.

CAÇADOR, S. B.; GRASSI, R. A. A economia capixaba no período pós-1990: O Processo de "Diversificação Concentradora". Revista Economia Ensaios, Uberlândia, v. 23, n. 2, 2009.

CAMPOS NETO, C. A. S. et al. Portos brasileiros 2009: ranking, área de influência, porte e o valor agregado médio dos produtos movimentados. Rio de Janeiro: Ipea, 2009 (Texto para Discussão, n. 1408).

CASTRO, Lavínia B. Privatização, Abertura e Desindexação: a primeira metade dos anos 90 (1990-1994). In: GIAMBIAGI, Fábio (Org.). Economia brasileira contemporânea: (1945-2004). Rio de Janeiro: Elsevier, 2005. 425 p.

COMPANHIA DOCAS DO ESPÍRITO SANTO (CODESA). Relatório da Administração 2011. Disponível em: <www.portodevitoria.com.br>. Acesso em: 25 de fevereiro de 2013.

DINIZ, Célio Campolina. A questão regional e as políticas governamentais no Brasil. Belo Horizonte: Cedeplar, Face, UFMG, 2001. (Texto para discussão n.159). 
FEIJÓ, Carmem Aparecida; RAMOS, Roberto Luis Olinto (Org.). Contabilidade Social: a nova referência das contas nacionais do Brasil. 3 ed. rev. e atual. Rio de janeiro: Elsevier Campus, 2007, 326 p.

FELIPE, Ednilson Silva. Fundap e Economia capixaba: qual a verdadeira encruzilhada? Vitória, ES, 2012. Disponível em: <www.economiacapixaba.wordpress. com >. Acesso em: 20 de fev. 2013.

FREITAS, F. (coord). Matriz de Absorção de Investimento e Análise de Impactos Econômicos. Rio de Janeiro: UFRJ, Instituto de Economia, 2009.

GRASSI, Robson, CAÇADOR, Sábio B. A Evolução Recente da Economia do Espírito Santo: Um Estado Desenvolvido e Periférico? In: ENCONTRO NACIONAL DE ECONOMIA, XXXVII, 2009, Foz do Iguaçu. Anais eletrônicos... Disponível em: <http://www.anpec.org.br/encontro_2009.htm>, Acesso em: 20 jan. 2013.

GUILHOTO, J. J. M. (2011). Análise de Insumo-Produto: Teoria, Fundamentos e Aplicações. Livro em Elaboração. Departamento de Economia. FEA-USP. Disponível em < http: \\mpra.ub.unimuechen.de/32566/2/MPRA_paper_32566.pdf >. Acesso em: 01 de mar. 2012.

HIRSCHMAN, A. O. Estratégia do desenvolvimento econômico. Rio de Janeiro: Fundo de Cultura, 1961. Edição original de 1958.

INSTITUTO BRASILEIRO DE GEOGRAFIA E ESTATÍSTICA (IBGE). Censo 2010. Disponível em: <www.censo2010.ibge.gov.br>. Acesso em: 15 de março de 2013.

INSTITUTO JONES DOS SANTOS NEVES (IJSN). Investimentos anunciados para o Espírito Santo 2011-2016. Vitória, ES, 2012. Disponível em: <www.ijsn. es.gov.br>. Acesso em: 8 de ago. de 2012.

IPEADATA. Diversos dados nacionais, regionais (Espírito Santo e Brasil) e setoriais sobre PIB calculados a preços constantes (em reais de 2000) para o período 19902009. Disponível em: <www.ipeadata.gov.br>. Acesso em: 01 de março de 2013.

KURESKI, R.; NUÑEZ, B. C; RODRIGUES, R. L. Multiplicadores de emprego e renda da indústria brasileira de celulose, papel e gráfica em 2003: uma aplicação da matriz de insumo-produto In: Anais do Congresso Brasileiro de Economia e Sociologia Rural, 45, 2007, Londrina - PR: SOBER, 2007, 19 p.

LEONTIEF, Wassily W. A economia do insumo-produto. 2 ed. - São Paulo: Nova Cultural, 1986. XVII 226 p. (Os economistas) 
LOPES, Luiz Martins; VASCONCELlOS, Marco Antonio Sandoval de (Org.). Manual de macroeconomia: nível básico e intermediário. 3. Ed. São Paulo, SP: Atlas, 2009, 388 p.

MAGALHÃES, M. A.; TOSCANO, V. N. Concentração de investimentos e interiorização do desenvolvimento no Espírito Santo. Vitória: IJSN, 2010. (Texto para Discussão, n. 11).

, Vocação para exportar: uma avaliação retrospectiva dos padrões de comércio exterior do estado do Espírito Santo (1996-2010). Vitória: IJSN, 2011 (Texto para Discussão, n. 34)

MIGUEZ et al. Uma proposta metodológica para a estimação da Matriz de Absorção de Investimentos para o período 2000-2009. Rio de Janeiro: IPEA, 2014 (Texto para Discussão, n. 1977)

MINISTÉRIO DO DESENVOLVIMENTO, INDÚSTRIA E COMÉRCIO EXTERIOR (MDIC). Conhecendo o Brasil em números, 2010. Disponível em: <www.mdic.gov.br>. Acesso em: 01 de mar. 2013.

MORANDI, A. M. et al. Convergência de Renda e dinâmica regional no Espírito Santo. In: ENCONTRO DE ECONOMIA DO ESPÍRITO SANTO, 3, 2012, Vitória. Anais eletrônicos... Disponível em: <http: \\www.encontroeconoiaes.com/ index.html>. Acesso em: 10 fev. 2013.

MORANDI, A. M. et al. Implantação da Companhia Siderúrgica UBU: Avaliação de Impacto a partir da Matriz de Insumo-Produto do Espírito Santo. Trabalho apresentado no II Encontro de Economia do Espírito Santo. Vila Velha. 2011. Disponível em: <http://www.encontroeconomiaes.com>. Acesso em: 12 de março de 2012.

MOTA, Fernando Cezar Macedo. Integração e dinâmica regional: o caso capixaba (1960-2000). 161 f. Tese (doutorado) - Universidade Estadual de Campinas, Instituto de Economia, 2002.

MYRDAL, G. Teoria econômica e regiões subdesenvolvidas. Belo Horizonte: Biblioteca Universitária - UFMG, 1960. Edição original de 1957.

PERROUX, F. O conceito de pólo de desenvolvimento. In: SCHWARTZMAN, J. (Org.). Economia regional: textos escolhidos. Belo Horizonte: Cedeplar, p. 145156, 1977. Edição original de 1955. 
ROCHA, Haroldo Corrêa. Formação econômica do Espírito Santo e sua lógica empresarial. In: GUALBERTO, João, DAVEL, Eduardo. (orgs.). Inovações organizacionais e relações de trabalho: ensaios sobre o Espírito Santo. Vitória: EDUFES, 1998. p. 33-75.

ROCHA, H. C. e MORANDI, Angela Maria. Cafeicultura e Grande Indústria: a transição no Espírito Santo 1955-1985. 1 ed. Vitória: Fundação Ceciliano Abel de Almeida, 1991.

RUIZ, R. M. e CROCCO, M. A. Plano de Desenvolvimento da Rede de Cidades do Espírito Santo. Relatório de Pesquisa. Belo Horizonte - MG, 2009.

SECRETARIA DE ESTADO DE ECONOMIA E PLANEJAMENTO (SEP). Espírito Santo 2025: plano de desenvolvimento. Vitória: SEP/MACROPLAN, 2006.

Recebido em 11.03.16

Aprovado em 27.11.17 